\title{
Política de avaliação externa: o discurso da qualidade ou a qualidade do discurso?
}

\author{
External evaluation policy: the speech quality or the quality of the speech?
}

Política de evaluación externa: ¿̨el discurso de la calidad o la calidad del discurso?

Rozemeiry dos Santos Marques Moreira ${ }^{1}$ Universidade Federal de Mato Grosso do Sul

Waléria Andrade Martins ${ }^{2}$ Universidade Federal de Mato Grosso do Sul

Resumo: Este artigo aborda o discurso da qualidade da política de avaliação externa e a qualidade do discurso da escola com base no que se entende por qualidade da educação na Constituição Federal de 1988, na Lei de Diretrizes e Bases da Educação Nacional de 1996 e no tex to da política de avaliação externa. As peculiaridades de cada escola tendem a dificultar a interpretação do texto da política, sobretudo em relação à qualidade, por ser um conceito relacional, de modo que traduzir políticas em práticas implica sua recriação em face de contextos distintos e por diferentes sujeitos. Assim, o discurso de qualidade nem sempre ganha forma e poder naquilo que o texto enuncia, mas na representação discursiva dos que atuam na escola.

Palavras-chave: Políticas Públicas de avaliação externa. Qualidade do desempenho escolar. Performatividade.

\begin{abstract}
This article covers the speech of the External Evaluation Policy and theschool speech based on what it is understood by Quality Education in 1988 Federal Constituion, according to the 1996 Law of Guidelines and Bases of the National Education and in the text of the External Evaluation. The peculiarities of each school tend to make them difficult to interpret the Policy text, mainly in relation to quality for being a relational concept so that translating policies into practice involves recreating them in face of diferente contexts and by diferente subjects. So, the quality speech is not Always understood and it can be what the text says, but in the discursive representation of those who work at school.
\end{abstract}

Keywords: Public Policy of external evaluation. Quality of the school performance. Perfomativity.

Resumen: Este artículo aborda el discurso de la calidad de la política de evaluación externa y la calidad del discurso de la escuela de acuerdo con lo que se entiende por calidad de la educación en la Constituição Federal de 1988, en la Lei de Diretrizes e Bases da Educação

\footnotetext{
1 Doutora de Educação pela Universidade Federal de São Carlos (UFSCar). Docente do Curso de Pedagogia da Universidade Federal de Mato Grosso do Sul. Campus de Três Lagoas-Mato Grosso do Sul. Brasil. E-mail: rozemeiry.moreira@ufms.br. Lattes: http://lattes.cnpq.br/9604739993632419. ORCID: https://orcid.org/0000-0001-9783-5626.

2 Doutora de Educação pela Universidade Federal de São Carlos (UFSCar). Docente do Curso de Matemática da Universidade Federal de Mato Grosso do Sul. Campus de Três Lagoas-Mato Grosso do Sul. Brasil.E-mail: waleria.martins@ufms.br.Lattes: http://lattes.cnpq.br/3951161839235387.ORCID: https://orcid.org/0000-0002-5061-214X.
} 
Nacional de 1996 y en el texto de la Política de evaluación externa. Las peculiaridades de cada escuela suelen dificultar la interpretación del tex to de la política, sobre todo en lo que se refiere a la calidad, por ser un concepto relacional, de modo que traducir políticas en acciones conlleva su recreación delante de conceptos distintos y de diferentes sujetos. Por tanto, el discurso de calidad no siempre adquiere forma y poder en lo que el tex to enuncia, sino en la representación discursiva de los que actúan en la escuela.

Palabras clave: Políticas Públicas de evaluación externas. Calidad del rendimiento escolar. Performatividad.

Recebido em: 15 de maio de 2021

Aceito em: 16 de agosto de 2021

\section{Introdução}

Neste artigo, pretende-se apresentar uma breve abordagem sobre um tema amplo e complexo referente aos discursos de qualidade, que se convertem em metas de políticas de avaliação externa.

Nesse intuito, buscam-se respostas sobre qual discurso de qualidade da política de avaliação externa tende a prevalecer no cenário educacional: O que os documentos elegem, ou o que se alcança nas práticas discursivas escolares? O que vem a ser qualidade no texto da política? Qual é a qualidade da prática? As respostas exigem, inicialmente, o entendimento do significado da palavra qualidade para, posteriormente, ser recriada em relação a um contexto distinto e por diferentes sujeitos.

Isso posto, vale a pena lembrar que qualidade é uma palavra flexível, intencionalmente definida por quem a expressa, podendo impor ou induzir comparações ou descontinuidades sobre a representação, o discurso e o conhecimento ao estabelecer diretrizes e bases para que a educação se efetive.

O enunciado qualidade na educação nos últimos anos vem sendo reiterado em diferentes instâncias educacionais. Nos anos 2000, por exemplo, ocorreu em Dacar, Senegal, o Fórum de Educação para Todos (Compromisso de Dacar). Nele, foi diagnosticado que a agenda firmada na Conferência Mundial sobre Educação para Todos, ocorrida em 1990, em Jomtien, Tailândia, fora negligenciada por muitos países (UNESCO, 2008).

No fórum, que teve a participação de 164 países, entre eles o Brasil, foram estabelecidas metas a serem cumpridas pelos países signatários até 2015. Os participantes firmaram acordo para expandir as oportunidades educacionais e reduzir as desigualdades. A partir de então, a Organização das Nações Unidas para a Educação, a Ciência e a Cultura (UNESCO) vem 
monitorando o cumprimento das metas e apresentando relatórios anuais sobre a qualidade na efetivação da agenda de Educação para Todos.

O Relatório de monitoramento de Educação para Todos - Brasil 2008: Educação para Todos em 2015: alcançaremos a meta? (UNESCO, 2008) apresenta como os governos dos países participantes têm prosseguido em relação às metas de Educação para Todos. No relatório, os resultados referentes ao objetivo 6, aprovado na Conferência de Dacar de 2000, relaciona qualidade a índices para:

6. Melhorar todos os aspectos da qualidade da educação e assegurar a excelência de todos, de forma que resultados de aprendizagem reconhecidos e mensuráveis sejam alcançados por todos, especialmente em alfabetização linguística e matemática e na capacitação essencial para a vida (UNESCO, 2008, p. 9).

Esse objetivo apreende qualidade sobre múltiplos fatores e regulações que permeiam a educação, de modo que qualidade é, sem dúvida, uma palavra constante na educação, aparecendo em diversos textos, documentos, leis, fóruns, congressos, declarações de organismos nacionais e internacionais, políticas, planos, programas, projetos e manifestações etc. Parece, ainda, crucial concordar que toda "discussão acerca da qualidade da educação remete à definição do que se entende por educação" (DOURADO; OLIVEIRA, 2009, p. 203).

Por um lado, essas considerações sinalizam que a qualidade na legislação da educação é o princípio de sua efetividade. Desse modo, a política de avaliação externa foi instituída pela Constituição Federal de 1988 (art. 206, inc. VII) para garantir o padrão de qualidade da educação nacional. Mais tarde, essa ferramenta de monitoração foi regulamentada pela Lei de Diretrizes e Bases da Educação Nacional de 1996 (art. $9^{\circ}$, inc. VI), definindo as prioridades e melhorias da qualidade de ensino na escola.

Por outro lado, é fundamental significar qualidade na gestão de uma escola como ações que viabilizam a finalidade de educar. Com isso, a complexidade está em criar condições para que a avaliação externa seja uma atividade pedagógica processual porque produz autorreflexão sobre a realidade do desempenho dos estudantes, em busca da melhoria da qualidade na educação de determinada escola.

No caso da política de avaliação externa da educação básica, busca-se identificar a dimensão da qualidade como meta de desempenho dos estudantes. Em decorrência, tal política impõe à gestão escolar refletir sobre a qualidade do currículo ensinado e o que se propôs avaliar.

Nesse sentido, os enunciados sobre a qualidade da educação e, em especial, sobre a qualidade do desempenho nas avaliações externas merecem atenção quanto às suas regularidades no contexto educacional, em meio às dispersões sobre sua finalidade. Para Foucault (2014, p. 45), quando descrevemos um conjunto de enunciados que apresentam em 
comum uma regularidade em uma ordem, funcionamentos e transformações "entre os objetos, os tipos de enunciação, os conceitos, as escolhas temáticas", estamos diante das chamadas formações discursivas, que nos permitem reconhecer discursos que circulam socialmente.

A formação e a transformação dos discursos se dão segundo regras de enunciabilidade, ou seja, regras daquilo que é possível dizer em dada época. Daí chamar de discurso "um conjunto de enunciados, na medida em que se apoiem na mesma formação discursiva" (FOUCAULT, 2014, p. 132). Essa definição de discurso mostra que os enunciados materializam as práticas discursivas. Só existe discurso se houver um sentido histórico materializado na e pela linguagem.

Para dar corpo às reflexões aqui articuladas, este trabalho se organiza da seguinte forma: primeiro, aborda-se o discurso de qualidade no texto da política de avaliação externa; em seguida, destaca-se o sentido de qualidade no discurso da escola. O desenvolvimento metodológico é mediado pelos estudos de Stephen Ball e Michel Foucault, entre outros.

Enfim, as reflexões consideram ser possível confirmar que o predomínio de um discurso nunca é neutro e que o discurso de qualidade sempre esteve presente no contex to da educação, da escola, da política educacional e da política de avalição externa.

\section{Política de avaliação externa: o discurso da qualidade}

Muito já se discutiu em estudos e pesquisas sobre avaliação externa e seus resultados na classificação da qualidade das escolas. No entanto, em algumas instituições escolares, o discurso de qualidade representa apenas uma pontuação emudecida em relatórios, sem as devidas reflexões sobre o trabalho pedagógico.

Assim, a inquietação sobre o discurso de qualidade da avaliação externa ganha forma e apresenta estímulos para se pesquisar sobre a melhoria da escola, pois "é de natureza da avaliação promover aprimoramentos institucionais, subsidiando-os com os dados da realidade que capturam e que disponibilizam para que os atores se engajem ativamente no processo de qualificação em curso" (SORDI, 2012, p. 164). Nesse sentido, os resultados da avaliação externa correspondem a uma qualidade a ser alcançada pela constante busca da melhoria do conhecimento, da reorganização curricular entre o que se está ensinando e o que deveria ser mais bem ensinado, da estrutura organizacional da escola para dar condições à efetivação do ensino e aprendizagem e da formação continuada de professores em serviço. Assim, a avaliação não deve ser restrita apenas aos resultados quantitativos obtidos pelos alunos, pela pontuação alcançada pela escola ou pela classificação entre escolas.

Regulamentada pelo Ministério da Educação (MEC), a política de avaliação externa é constituída por um Sistema de Avaliação da Educação Básica (SAEB) desde 
1990, passando por várias estruturas até chegar ao formato atual. Em sua organização, agrega um conjunto de avaliações externas em larga escala de Língua Portuguesa e Matemática, aplicadas aos estudantes participantes a cada dois anos, também se utilizando de questionário socioeconômico à comunidade escolar.

Em relação aos resultados, ainda que o SAEB induza a gestão escolar a mecanismos de autonomia para o uso dos resultados, observa-se a imposição predominante de qualidade apenas sobre o conhecimento de Língua Portuguesa e Matemática, em detrimento das demais áreas do conhecimento do currículo ensinado na escola.

Em sua história, o SAEB ocorre por meio de dois processos de avaliação. Um deles é a Avaliação Nacional da Educação Básica (ANEB), realizada por amostragem de estudantes das redes de ensino, com foco na gestão dos sistemas educacionais. O outro processo refere-se à Avaliação Nacional do Rendimento Escolar (ANRESC), cuja finalidade é avaliar a qualidade do ensino da escola de forma censitária, ou seja, para todos os estudantes matriculados nas séries avaliadas.

O MEC, em parceria com o Instituto Nacional de Estudos e Pesquisas “Anísio Teixeira” (INEP), implementou a política de avaliação externa à escola para o diagnóstico do desempenho dos estudantes e dos fatores que podem interferir sobre a referência de qualidade estabelecida pela política em questão. Nesse caso, a implementação é sobre o que será avaliado e como será realizado, constituindo matrizes de referência de itens para compor o teste como instrumento de medida utilizado. Nessa perspectiva, Horta Neto (2010, p. 89-90) esclarece que as matrizes de referência "estão intimamente relacionadas com o currículo escolar, para que a medida tenha relação com o processo que se desenvolve na escola”

Nesses termos, a garantia de padrão de qualidade (BRASIL, 1988, 1996) se confirma em política educacional quando o MEC e o INEP esperam que os estudantes do $5^{\circ}$ ano do ensino fundamental alcancem médias numéricas menores que os de $9^{\circ}$ ano e estes alcancem médias menores que as atingidas pelos estudantes de $3^{\mathrm{a}}$ ou $4^{\mathrm{a}}$ série do ensino médio. Desse modo, o resultado torna-se um indicativo da qualidade da educação básica no Brasil, para a elaboração, monitoramento e aprimoramento de políticas educacionais com base em evidências.

A avaliação externa é, portanto, condição intrínseca ao processo de qualificação da educação básica, por ser pautada nos resultados do desempenho dos estudantes. Aqui se observa tanto a padronização da avaliação quanto a do currículo, no sentido de vincular a qualidade do resultado à qualidade do currículo trabalhado na escola. 
O pacto negociado dessa qualidade desperta o interesse em saber a quem serve a avaliação externa, ou se a avaliação externa contribui ou não para a melhoria da qualidade da educação básica nas escolas. Isso porque nem sempre a qualidade definida pela política de avaliação externa é a mesma definida pela escola, considerando sua realidade e necessidades distintas.

Muitas vezes, a escola é responsabilizada por não atingir os resultados esperados pela política de avaliação externa, e a ausência da análise sobre os números alcançados tende a se agravar para a gestão escolar interessada em soluções para a melhoria da qualidade da aprendizagem dos alunos avaliados. Por isso, aponta-se que é preciso buscar entender os resultados da avaliação externa como atividade do processo de ensino e aprendizagem da escola, e não como uma etapa da agenda de avaliação implantada pelo MEC/INEP.

Tal situação é esclarecida por Ball e Mainardes (2011), quando esclarecem sobre a forma como o texto da política se relaciona com a prática escolar. Os autores explicam que essa relação não deve ser linear e pontual, como se em política houvesse um binarismo entre os beneficiários de primeira ordem - os que elaboram as políticas - e os de segunda ordem aqueles que executam e que são atingidos pelas políticas, seja de modo positivo ou negativo.

O que encontramos na realidade ainda é um binarismo linear que impede a interação entre o texto da política e a prática de muitas escolas, em virtude da falta de organização do tempo escolar para leitura e conhecimento de seu conteúdo, objetivando uma cultura escolar que se disponha à discussão coletiva para a devida interpretação no intuito de responder os seguintes questionamentos: “O que esta política quer dizer?”, “O que ela está dizendo?”, “O que nós devemos fazer?” para implantá-la na escola (Ball apud AVELAR, 2016, p. 7).

As respostas para tais questões motivam a busca de uma aprendizagem necessária na escola, visto que traduzir políticas em práticas é extremamente complexo porque tanto a tradução quanto o discurso podem ser suficientemente isolados para pôr políticas em práticas na escola, e, portanto, pode silenciar ou induzir a finalidade do texto original, proveniente do contex to macro (sistema de ensino), diante da particularidade do contex to local (escola). Assim, Maguire e Ball (2011, p. 176) explicam que "políticas são construídas dentro e ao redor de discursos específicos que são eles mesmos conjuntos de práticas que sistematicamente produzem os objetos dos quais falam [...]”, e essa condição, segundo os autores, impede a interpretação do texto da política de modo que possa se adequar à realidade local. Os gestores e professores do espaço escolar assumem os discursos como verdadeiros, mas não têm autoridade para determinar quais saberes devem ser postos em circulação. 
Portanto, políticas são estratégias discursivas. Em Foucault (2014, p. 208-209), os discursos se tornam um “[ [...] conjunto de condições de acordo com os quais uma prática é exercida, de acordo com os quais essa prática dá origem parcial ou totalmente a novas declarações, e de acordo com o qual ela pode ser modificada”.

Seguindo esse entendimento, tem-se que o discurso de controle de qualidade determinado pela política ganha forma e poder disciplinador. Concorda-se com Foucault (1996, p. 34), entendendo que "a disciplina é um princípio de controle da produção do discurso. Ela lhe fixa os limites pelo jogo de uma identidade que tem a forma de uma reatualização permanente das regras" entre gestores e professores da escola.

Então, quando se tenta entender o discurso de qualidade da política de avaliação externa, que se faz pela organização disciplinar na escola, ao participar da avaliação e considerar que a pontuação alcançada representa a qualidade de desempenho dos estudantes, o processo se efetiva em polifonia com outros textos. Assim, tem-se que a regulação dos resultados e o cumprimento das normas deveriam acontecer por meio da leitura do texto da política e de documentos normativos do MEC/INEP, "tendo em vista o jogo político em que foi produzido, sempre em polifonia com outros textos, visto que política representa textos em ação" (BOWE; BALL; GOLD, 1992, p. 21).

Importa considerar com os autores que os "textos das políticas têm uma história representacional, mas não entram num espaço institucional (e social) vazio, sendo, portanto, recriados a cada leitura" (BOWE; BALL; GOLD, 1992, p. 21), com vozes explícitas e implícitas, carregados de influências, mediações e contradições que envolvem a ideia do texto e a intenção da prática.

Nesse aspecto, é preciso reconhecer que as escolas têm histórias, encontram-se envolvidas por profissionais, organização e práticas que as diferenciam, ainda que compondo um mesmo sistema de ensino. De modo prospectivo ou retrospectivo em relação à história da escola, os sentidos apresentam-se por meio de diferentes formas de interpretação em virtude de cada escola ser constituída de lugares, de sujeitos com características próprias.

Claramente, os discursos e as interpretações não reverberam da mesma forma em todas as escolas. Isso porque a escola, local em que as políticas se materializam, depende da adesão e implementação dos que fazem a política acontecer, ou seja, gestores e professores da unidade. Um exemplo é o da própria política de avaliação de sistema, também conhecida como política de avaliação externa em larga escala, que se caracteriza por um discurso representativo de como essa avaliação ocorre, isto é, externamente à escola.

As condições de como a avaliação é elaborada e aplicada de modo externo à escola tendem a produzir uma representação discursiva de que também seu resultado é externo à 
escola, isto é, não há relação de pertencimento dos resultados como possibilidade de refletir sobre os índices alcançados. Isso pode conduzir a gestão de algumas escolas a não tomar decisões diante do resultado, pois estará à espera de que os órgãos formuladores e implementadores da política de avaliação externa pensem e tomem decisões para a solução de seus resultados. Tal decisão da escola não se justifica, pois, ao retornarem para escola os resultados, esses órgãos expressam a autonomia da gestão em considerar a especificidade do local e suas características próprias para as devidas soluções.

Assim, a política de avaliação externa se consolidou em um importante instrumento gerador de análises, explicações e críticas da ação educativa, da qualidade de ensino e da aprendizagem dos estudantes de todas as escolas do sistema de ensino nacional. Essas atribuições representam o discurso do pensamento, do agir e do poder de algumas vozes como verdade, em uma espécie de disputa discursiva nem sempre realizável no contexto da prática.

É nessa condição que o discurso produz relações de poder, de desejo criador de verdades e de conhecimentos na gestão escolar, que, por conseguinte, privilegia ou exclui formas e práticas organizacionais, relações e tipos de interação (BALL; MAINARDES, 2011). Entender essa dinâmica é diferenciar linguagem e discurso, visto que a linguagem reconhece a si mesma como mundo; o discurso, ao contrário, vê a si mesmo como representação do mundo (FOUCAULT, 1997, 2012).

Segundo os autores, se tomarmos o sujeito como objeto do conhecimento, sua linguagem resultará em mudança histórica na formulação do texto de uma política e, por conseguinte, seu discurso será uma representação transparente de coisas e ideias situadas fora do texto, ou seja, na prática, em um contex to real. Entretanto, é preciso observar que a qualidade definida no texto da política de avaliação externa tem uma linguagem articulada ao poder do discurso da qualidade a ser alcançada para a solução do baixo desempenho escolar. Isso se faz por meio do controle a distância pelo Estado sobre o contexto avaliado, já que detém a supremacia da publicização dos resultados, e pelo ranking da qualidade alcançado pela escola.

Por um lado, não se pode ignorar que a necessidade de informar a sociedade e a comunidade sobre qual a melhor escola ou melhor educação por meio do discurso comparativo entre pontuações tem produzido o efeito de ranking da qualidade das instituições escolares, rapidamente divulgado pela mídia com os resultados de cada edição da avaliação externa.

A constante divulgação da pontuação da escola tem apontado a organização do trabalho pedagógico, que é processual e não depende só da boa vontade do gestor, do professor, da estrutura organizacional, mas sobretudo do coletivo da escola na 
identificação e solução do porquê da não aprendizagem dos alunos, do currículo proposto e, portanto, trabalhado, da formação de professores e da fragilidade de conhecimentos acumulados pelo aluno. Nessa perspectiva, ainda é possível encontrar pontos positivos no ranqueamento, tais como: a valorização dos profissionais da escola mais bem pontuada, a preferência na procura por matrículas e a motivação para a competição por melhores posições no ranking entre as escolas.

Em outra perspectiva, que ganha força a partir da adesão da escola imposta pela política de avaliação externa, o ranqueamento representa novas formas de organização e de relações de trabalho no interior das escolas, em todos os aspectos performativos do currículo e da formação continuada de professores, porque o resultado classifica a qualidade da unidade escolar e se serve à meritocratização.

Importa então referir os resultados da avaliação externa como dados sobre avanços e eventuais retrocessos do desempenho escolar que precisam ser acompanhados por todos da escola. De posse do enunciado de seus objetivos, cabe o confronto com os resultados para, consequentemente, serem criadas as possíveis intervenções em face das necessidades diagnosticadas.

No entanto, à medida que as escolas alcançam sua melhor posição, algumas têm-se apropriado do discurso de qualidade sem no entanto deterem o conhecimento sobre o porquê e o para quê da avaliação. A ausência desse conhecimento confirma que a política da avaliação externa não efetivará seus resultados como melhoria da qualidade da prática real, pois os resultados representam discursos sobre posições numéricas ocupadas em um ranking entre escolas.

\section{Política de avaliação externa: a qualidade do discurso}

É certo que a avaliação existe muito antes da escola. Essa certeza leva a indagar por que a avaliação foi tão apropriada pela escola para diagnosticar o conhecimento pela marca do poder, da classificação e da comparação a um perfil de qualidade desejado.

Entre as respostas possíveis, afirma-se que a avaliação no contexto escolar não deveria prestar-se a esse papel. No entanto, o modelo de avaliação externa sob esse princípio ganhou relevância com as reformas educacionais, a partir da década de 1990, produzindo mudanças de grande impacto na estrutura organizacional da escola para a solução do baixo rendimento da aprendizagem.

Tal realidade gerou a necessidade de se buscarem ações que permitissem alcançar a qualidade da educação, em cumprimento ao modelo regulador e avaliador imposto pelo Estado, em várias instâncias da organização escolar. Assim, a avaliação tornou-se o instrumento para reestruturação do ensino, padronização dos currículos, definição de 
qualidade de escola e outros. Trata-se de um modelo de avaliação que tem servido como instrumento a um modelo de Estado avaliador por exercer severo controle e forte fiscalização (DIAS SOBRINHO, 2002) sobre a educação oferecida pela escola, que, por conseguinte, passou a criar práticas gestionárias eficazes.

Importa, então, abarcar as dimensões desses processos e refletir acerca da qualidade do discurso de que a escola se apropriou considerando os resultados de um número de avaliações externas das quais participou, com periodicidade e características diferentes sobre o desempenho escolar. Desse modo, a escola passou a adotar um discurso de qualidade já definido, bastando-lhe cumprir o que já foi determinado externamente. Com isso, os resultados tendem a permanecer em relatórios sem a devida apropriação, planejamento e análise com o currículo ensinado.

Dourado e Oliveira (2009, p. 243) consideram, no entanto, que a concepção de qualidade também "vislumbra as possibilidades e os limites interpostos a essa prática e sua relação de subordinação aos macroprocessos sociais e políticos delineados pelas for mas de sociabilidade vigentes". Por exemplo, a avaliação externa causa tensão, expectativa e temor em situações que antecedem a data da avaliação na escola, produzindo diferentes iniciativas entre gestores e professores na preparação antecipada dos estudantes, como os treinos para participar da avaliação externa. É preciso ponderar que todas as escolas não terão a mesma interpretação diante da avaliação externa e, consequentemente, a mesma decisão sobre os resultados para mudanças e melhoria da educação local.

Vale destacar que a legitimidade técnica da avaliação externa na escola tem evidenciado dificuldades para trabalhar com os resultados na prática pedagógica, pois esta é fundada em um poder normalizador inscrito em um discurso de qualidade. A percepção de que o saber está inescapavelmente ligado ao poder, em decorrência de sua vinculação ao discurso, tem permitido afirmar que as práticas produzidas na escola são condicionadas à fabricação ou fixação da verdade como um sistema de procedimentos ordenados para a produção, regulamentação e circulação de afirmações sobre o que está sendo imposto como verdade. Ou seja, não necessariamente se refere à qualidade definida pelo projeto político-pedagógico da escola e sobre o currículo ensinado, mas sobre o que a avaliação determina para ser avaliado.

Nessa perspectiva, “as 'melhores' escolas não são aquelas que conseguem o máximo em termos de aprendizagem discente, mas aquelas que são capazes de filtrar e selecionar sua clientela mais convenientemente” (BALL, 1998, p. 209). Assim, o aluno é posicionado e avaliado de forma diferente no contexto considerado mercado educacional, cujo “[ ...] processos de competição institucional [...] apela a uma economia de valor do/a 
estudante" (BALL, 2001, p. 108). Logo, nesse embate por melhores escolas no mercado educacional, o resultado da avaliação é o produto que qualifica a qualidade da escola.

Essa conjuntura pode remeter ao modo, em geral, perverso em como a representação política se efetiva em uma escola, isto é, pela dupla constituição do discurso como poder e como linguagem, muitas vezes pela mediação de uma ordem externa aceita como inevitável e naturalizada. Portanto, a decisão política sobre o pedagógico é prescrita como correta para que se cumpra sem os devidos reconhecimentos da(s) cultura(s), dos valores, conhecimentos e dificuldades existentes na escola. Tais circunstâncias podem dificultar ou até impedir a construção de uma política local assumida socialmente por todos da escola.

Assim, no controle de qualidade da escola, cabe afirmar que se trata de efeitos de uma concepção meritocrática na educação, moldada pela regulação do tempo e espaço escolar, com base em um currículo padronizado, cujo desempenho é monitorado pela avaliação padronizada externa à escola. A configuração dessa realidade é amplamente discutida por Ball (2002, 2005, 2010) e contribui para novas reflexões sobre o efeito do controle de qualidade causado pela performatividade nos professores sobre o que e como ensinar para a avaliação. Produzindo a sensação de trabalharem "sobre a possível certeza de ser sempre vigiado" (BALL, 2010, p. 39).

$\mathrm{O}$ efeito do controle de qualidade pela performatividade nos gestores e professores da escola tem causado:

[...] instabilidade de ser julgado de diferentes maneiras, por diferentes meios, por meio de diferentes agentes; o "levar a termo" das performances - o fluxo de demandas, expectativas e indicadores em constante mudança que nos fazem continuamente responsáveis e constantemente registrados […] (BALL, 2010, p. 39).

Seguindo esse pensamento, pode-se reconhecer as demandas causadas pela performatividade como princípio de responsabilização dos profissionais da escola pelo alcance de qualidade, notadamente configurado por tendências conflituosas, tensas e constantemente revisadas por um receituário que exalta a insegurança do que não se pode evitar em cumprir. Essa concepção tem causado aos gestores e sobretudo aos professores a “[...] insegurança ontológica, que coloca questões tais como 'Estamos fazendo o suficiente? Estamos fazendo a coisa certa? Nosso desempenho será satisfatório?’”(BALL, 2010, p. 39).

Nas múltiplas dimensões da gestão escolar, a segurança de melhoria da qualidade da escola é confrontada com a insegurança dos gestores e professores sobre saber fazer e a tomada de decisões sobre os processos e métodos de ensino, de aprendizagem, do currículo e da estrutura organizacional na escola. Essa realidade tem produzido novos 
cenários de escolas, envolvendo sujeitos, práticas e relações inautênticas criadas pela “alienação do eu relacionada à incipiente 'loucura' das demandas da performatividade” (BALL, 2010, p. 43). Tal imposição tem configurado a escola em busca de melhores posições no ranqueamento do desempenho escolar.

Além disso, será possível explicar como a gestão escolar tem administrado tantos dados da avaliação externa sob a lógica da performatividade? Aceitando esse desafio, parece claro que existem explicações sobre a atual condução do processo educacional, mediadas por novos termos e tendências teóricas, como a das fabricações ou da eficácia escolar. Trata-se do gerenciamento com intervenções educativas ocorridas na escola produzidas por atos de fabricações. A esse respeito, parafraseando Michel Foucault, Ball (2010, p. 44) esclarece:

Fabricações são versões de uma organização (ou pessoa) que não existe - elas não estão "fora da verdade", mas também não tratam de uma simples verdade ou de descrições diretas - elas são produzidas propositadamente para "serem responsabilizáveis".

Dessa maneira, considera-se que fabricações organizacionais ou de pessoas têm como foco a efetividade do mercado para a inspeção, apreciação, ou ainda a "ação que elas exercem sobre e dentro da organização - seu impacto transformador" (BALL, 2010, p. 44), em busca da qualidade já determinada, e não da qualidade que a escola elege coletivamente.

A rigor, as escolas sob efeito de uma inspeção têm tomado elementos e modos de funcionamento fabricados para legitimar e tornar visível uma organização auditável, por meio de mecanismos da performatividade expressos em documentos comprobatórios. Entre esses documentos estão "a base de dados, a reunião de avaliação, a análise anual, a elaboração de relatório, a publicação periódica dos resultados e das candidaturas à promoção, as inspeções e a análise dos pares" (BALL, 2005, p. 548).

A base para essa operacionalidade está no gerencialismo, eficácia e avaliação sob o discurso de qualidade, que concorrem para "localizar os indivíduos no espaço de uma organização hierárquica e eficientemente visível” (BALL; MAINARDES, 2011, p. 88), ou para conseguir excelência de escolas, pois constituem elementos que permitem informar a qualidade da educação oferecida aos consumidores, quando estes fazem suas escolhas no momento de matrícula.

Desse modo, a qualidade do discurso da escola com base nos resultados da avaliação externa consiste em dar sentido histórico materializado ao tex to da política de avaliação externa, lembrando que se trata de um discurso que se efetiva na e pela linguagem. 


\section{Concluindo}

À guisa de conclusão, pode-se afirmar que os cenários percorridos pela avaliação externa são decorrentes de reformas implantadas na educação brasileira nas últimas décadas do século XX, sob orientação das políticas neoliberais nos setores públicos, como educação, saúde e outros, subordinados a uma lógica econômica global. Assim, na intencionalidade dessa lógica "[ [...] faz sentido a afirmação de que no projeto neoliberal, o Estado mínimo é o máximo na avaliação” (SORDI, 2002, p. 67).

Tais características estão presentes no discurso dominante em políticas ao eleger uma referência de qualidade. E, de modo muito expressivo, os resultados das políticas de avaliação externa têm produzido procedimentos consensuais na escola em manter o discurso da qualidade em conformidade aos relatórios, amplamente divulgados pela mídia sem uma conferência analítica dos números alcançados.

Essas constatações podem ser percebidas em situações diversas no contexto escolar e pelas tramas discursivas da política de avaliação externa como sendo a grande verdade para a melhoria da qualidade, anunciando atitudes de responsabilização e competitividade como a salvação da qualidade das escolas públicas.

Nesse sentido, as considerações sinalizam que qualidade de escolas não se deve circunscrever apenas a médias de rendimento escolar, pois envolvem também as condições objetivas e subjetivas da organização, da gestão escolar e da dinâmica pedagógica.

Diante de tais circunstâncias, é possível identificar que a fragilidade ou a ausência de uma cultura de avaliação como parte do trabalho pedagógico tem alimentado a ideia de que os resultados da avaliação externa não pertencem à escola.

Importante ressaltar que um dos fatores que levam a esse entendimento na escola está vinculado ao tempo para a divulgação do resultado da avaliação, que só acontece no ano seguinte ao de sua aplicação, quando os alunos já não se encontram mais na série avaliada. Acredita-se que essa situação inibe a intervenção da gestão escolar em comparar o resultado com o currículo que a escola ensinou e o currículo avaliado, e como consequência prevalece o discurso da qualidade sobre a pontuação alcançada sem maiores reflexões por parte da escola sobre o que os resultados estão dizendo em relação ao currículo avaliado e a aprendizagem demonstrada.

Outro dado a ser considerado diz respeito aos relatórios dos resultados da avaliação externa, que por serem produzidos em uma linguagem técnica muitas vezes não é compreensível a todos os gestores e professores da escola, a exemplo dos gráficos de acertos e erros, que trazem dificuldades de interpretação dos conteúdos avaliados. 
Por essas e tantas outras dificuldades para interpretar e solucionar o que os dados apontam, a avaliação externa deixa de ter uma "validade consequencial” (VIANNA, 2003) na escola, como a iniciativa de a gestão escolar analisar com os professores os resultados objetivando promover mudanças nos aspectos organizacional, pedagógico e social da realidade escolar. Assim, o discurso de qualidade nem sempre ganha forma e poder naquilo que o texto enuncia, mas na representação discursiva dos que atuam na escola.

\section{Referências}

BALL, Stephen J. Mercados educacionais, escolha e classe social: o mercado como estratégia de classe. In: GENTILI, Pablo (org.). Pedagogia da exclusão: crítica ao neoliberalismo em educação. 4. ed. Petrópolis: Vozes, 1998, p. 196-227.

BALL, Stephen J. Diretrizes políticas globais e relações políticas locais em Educação. Currículo sem Fronteiras, S.l., v. 1, n. 2, p. 99-116, jul./dez. 2001. Disponível em: http://www.currículosemfronteiras.org. Acesso em: 19 maio 2021.

BALL, Stephen J. Reformar escolas/reformar professores e os terrores da performatividade. Revista Portuguesa de Educação, Braga, v. 15, n. 2, p. 3-23, 2002. Disponível em: DOI: https://www.redalyc.org/pdf/374/37415201.pdf. Acesso em: 19 maio 2021.

BALL, Stephen J. Profissionalismo, gerencialismo e performatividade. Cadernos de Pesquisa, São Paulo, v. 35, n. 126, p. 539-564, set./dez. 2005. DOI: https://doi.org/10.1590/SO10015742005000300002 .

BALL, Stephen J. Performatividades e fabricações na economia educacional: rumo a uma sociedade performativa. Educação e Realidade, Porto Alegre, v. 35, n. 2, p. 37-55, ago./set. 2010.

BALL, Stephen J. Entrevista. In: AVELAR, Marina. Entrevista com Stephen J. Ball: uma análise de sua contribuição para a pesquisa em política educacional. Archivos Analíticos de Politicas Educativas, Tempe (AZ), v. 24, n. 24, p. 1-16, 2016. DOI: https://doi.org/10.14507/epaa.24.2368.

BALL, Stephen J.; MAINARDES, Jefferson (orgs.). Políticas educacionais: questões e dilemas. São Paulo: Cortez, 2011.

BOWE, Richard; BALL, Stephen J.; GOLD, Anne. Reforming education and changing schools: case studies in Policy Sociology. London: Routledge, 1992.

BRASIL. Constituição da República Federativa do Brasil de 1988. Diário Oficial [da] República Federativa do Brasil, Brasília, DF, 5 out. 1988.

BRASIL. Lei n ${ }^{\circ}$ 9.394, de 20 de dezembro de 1996. Estabelece as diretrizes e bases da educação nacional. Diário Oficial [da] República Federativa do Brasil, Brasília, DF, 23 dez. 1996.

BRASIL. Portaria ministerial n ${ }^{\circ}$ 93 1, de 21 de março de 2005. Institui o Sistema de Avaliação da Educação Básica - SAEB, que será composto por dois processos de avaliação: a Avaliação Nacional da Educação Básica - ANEB, e a Avaliação Nacional do Rendimento Escolar ANRESC. Diário Oficial da União, Brasília, DF, 22 mar. 2005. Seção 1, p. 17. 
BRASIL. Portaria INEP n ${ }^{\circ} 47$, de 3 de maio de 2007. Estabelece a sistemática para a realização da Prova Brasil e da Avaliação Nacional da Educação Básica no ano de 2007. Diário Oficial [da] República Federativa do Brasil, Brasília, DF, 7 maio 2007.

DIAS SOBRINHO, José. Campo e caminhos da avaliação: a avaliação da educação superior no Brasil. In: FREITAS, Luiz Carlos de (org.). Avaliação construindo o campo e a crítica. Florianópolis: Insular, 2002. p. 13-61.

DOURADO, Luiz Fernandes; OLIVEIRA, João Ferreira de. A qualidade da educação: perspectivas e desafios. Cadernos CEDES, Campinas, v. 29, n. 78, p. 201-2 15, maio/ago. 2009. DOI: https://doi.org/10.1590/S0101-32622009000200004.

FOUCAULT, Michel. A ordem do discurso: aula inaugural no College d'e France, pronunciada em 2 de dezembro de 1970. Trad. Laura Fraga de Almeida Sampaio. São Paulo: Edições Loyola, 1996.

FOUCAULT, Michel. O poder simbólico. In: Vigiar e punir: nascimento da prisão. Trad. Raquel Ramalhete. 16. ed. Petrópolis: Vozes,1997. p. 22.

FOUCAULT, Michel. Por uma genealogia do poder. In: org. e rev. téc. Roberto Machado. 25. ed. São Paulo: Graal, 2012. p. 43. Microfisica do poder. Intr.,

FOUCAULT, Michel. A arqueologia do saber. 8. ed. Rio de Janeiro: Forense Universitária, 2014.

HORTA NETO, João Luiz. Avaliação externa de escolas e sistemas: questões presentes no debate sobre o tema. Revista Brasileira Estudos Pedagógicos, Brasília, v. 91, n. 227, p. 84-104, jan./abr. 2010. DOI: https://doi.org/10.24109/2176-6681.rbep.91i227.604.

MAGUIRE, Meg; BALL, Stephen J. Discursos da reforma educacional no Reino Unido e nos Estados Unidos e o trabalho dos professores. In: BALL, Stephen J.; MAINARDES, Jefferson (orgs.). Políticas educacionais: questões e dilemas. São Paulo: Cortez, 2011. p. 175-192.

SORDI, Mara Regina Lemes de. Entendendo as lógicas da avaliação institucional para dar sentido ao contexto interpretativo. In: VILLAS BOAS, Benigna M. F. (org.). Avaliação: políticas e práticas. Campinas: Papirus, 2002.

SORDI, Maria Regina Lemes de. A avaliação da qualidade da escola pública: a titularidade dos atores no processo e as consequências do descarte de seus saberes. In: FREITAS, Luiz Carlos de et al. Avaliação e políticas públicas educacionais: ensaios contrarregulatórios em debate. Campinas: Edições Leitura Crítica, 2012. p. 157-169.

UNESCO - Organização das Nações Unidas para a Educação, a Ciência e a Cultura. Relatório de monitoramento de Educação para Todos Brasil 2008. Educação para Todos em 2015: alcançaremos a meta? Brasília: UNESCO, 2008. Disponível em: http://unesdoc.unesco.org/images/0015/001592/159294por.pdf. Acesso: 19 maio 2021.

VIANNA, Heraldo Marelim. Avaliações nacionais em larga escala: análises e propostas. Estudos em Avaliação Educacional, São Paulo, n. 27, p. 41-76, jan./jun. 2003. DOI: https://doi.org/10.18222/eae02720032177. 